\title{
The Phonological Influence of Ethnic Community Languages in Learning Kiswahili, a Case of Kinyakyusa in Mbeya, Tanzania
}

\author{
Godson Robert Mtallo \\ Department of Business Administration, College of Business Education (CBE) - Dodoma Campus, P.o.Box 2077 \\ Dodoma, Tanzania \\ Harid Andrew Mwambula \\ Department of Communication Skills, Tanzania Institute of Accountacy, P.o.Box9522 Dar es Salaam, Tanzania
}

\begin{abstract}
It is noted that one language may have an influence in learning the other language. This influence may be vividly seen in different aspects such as phonology, morphosyntax as well as lexis. This paper focuses on investigating how the Ethnic Community Languages, henceforth ECLs, can phonologically influence the learning process of Kiswahili language. Kinyakyusa was taken as a sample to represent other Ecls in Tanzania to see its phonological influence in Learning Kiswahili. The study employed word lists, in depth interview and observations as data collection techniques. The findings revealed that, phonologically, speech sounds that are similar in Kinyakyusa and Kiswahili as a second language such as /p/, /t/, / / / , /f/, /s/ were easily learned. Learners were faced with some difficulties in pronouncing some utterances that are not found in Kinyakyusa but exist in Kiswahili. For instance, voiced alveolar trill sound /r/ was pronounced as voiced alveolar lateral sound /l/, voiceless dental fricative sound / $/$ / was pronounced as voiceless alveolar fricative sound /s/.
\end{abstract}

Index Terms-phonology, Kiswahili, Kinyakyusa, Ethnic Community Language (ECL), Tanzania

\section{INTRODUCTION}

\section{A. Background to the Problem}

It has been found that some researchers on linguistics show the great role played by first language in the process of learning a second language. It is argued that with the first language (herein L1) and second language (herein L2) that have some similar structures and patterns, learners of L2 will not face great difficulties different from where L1 and L2 are completely different from each other. This is because the presence of some similarities in terms of structures and language patterns in L1 and L2, learners of L2 will be transfering experienced knowledge from L1.

If children do not fully acquire their first language, they may have difficulty in becoming fully literate and academically proficient in the second language (Collier, 1992, 1995). Thierry (2010), found that the Chinese - English bilinguals' adults who are fluent in English whose first language is Chinese retrieve their native language when reading in English.

There are many studies on the role of first language in learning second language. Bada (2001), investigated Japanese learners who were learning to pronounce English sounds. His findings revealed that the phoneme $/ \mathbf{d} / \mathrm{replaced}$ with $/ \mathbf{t} / \mathrm{in}$ word final. Prince (1996), used 48 French University students with English as their L2. His study revealed that half of the group had to learn L2 words with their L1 equivalent translation condition. Lotto and Groot (1998), compared the $\mathbf{L 1} \rightarrow \mathbf{L} 2$ word learning strategy with picture $\rightarrow \mathbf{L 2}$ word learning to Dutch University (non-language) Italy was L1 and Dutch as L2. It was found that students were able to recall the Italian words faster if they used $\mathbf{L} 1 \rightarrow \mathbf{L} 2$ word learning strategy than if they used the picture $\rightarrow \mathbf{L} \mathbf{2}$ word learning strategy.

In spite of many studies on the influence of L1 in learning L2, it has been found that many of these have been done to European languages and to the learners of higher learning level. With evidence from the existing literature, few studies have been done on Bantu languages and specifically on Kinyakyusa in learning Kiswahili as an L2.

\section{B. Statement of the Problem}

Observation that has been done reveals that there are similarities of some lexical items and word order between Kinyakyusa and Kiswahili as a second language. However, there are errors in use of some vocabulary and pronunciations of speech sounds that come from Kinyakyusa during the process of learning Kiswahili as a second language. For example, some Nyakyusa people fail to pronounce correctly the voiced bilabial fricative sound /v/ instead pronounce it as voiceless bilabial-dental fricative sound /f/ in words like 'vitu' 'things' it is pronounced as 'fitu', vaa 'wear'pronounced as faa 'reasonable'. Also the voiceless palatoalveolar affricative sound $/ \theta$ '/ is pronounced as $/ \mathrm{ky} /$ in words like $\boldsymbol{c h}$ ai 'tea' which is pronounced as kyai.. 
This kind of study on the influence of first language in learning second language has been studied by many scholars in European languages like Dutch, Spanish, Bengali, French and English. However few scholars like Zabron (2012) investigated the challenges experienced by foreigners in learning Kiswahili in higher learning institutions. Zabron (2012) found that Spanish learners face difficulties in the area of pronunciation of some sounds and in forming plural form in Kiswahili words.

Hence, because of the relationship between Kinyakyusa and Kiswahili and other studies on the influence of first language in learning second language as mentioned above, for the best knowledge of the researcher no study has been done on the role of Kinyakyusa as a first language in learning Kiswahili as a second language. The study was based on the influence of Kinyakyusa in terms of phonology, morpho-syntactic and lexicon in the process of learning Kiswahili as a second language.

\section{Objectives of the Study}

Generally, this research has examined the role of Kinyakyusa as a first language in learning Kiswahili as a second language.The study is guided by the following specific objective:

(i) To investigate the phonological influence of Kinyakyusa in learning Kiswahili as a second language.

\section{Research Question}

The research was guided by the following questions:-

(i) What are the phonological influences of Kinyakyusa as the first language in learning Kiswahili as a second language?

\section{E. Significance of the Study}

The findings from this research will help teachers of second language consider the influences of first language in the process of learning second language. Thus, teachers should be able to assist learners when the knowledge of the first language hinders efficiency in learning the second language.

Also the researcher will gain knowledge and experience on the relationship between Kinyakyusa and Kiswahili language. Moreover, the researcher will gain skills in the general realm of research.

Furthermore, the findings from this study will be helpful to scholars and researchers as will be used as a reference while investigating the related problems in linguistic field and further research.

\section{F. Scope of the Study}

The study is on the role of Kinyakyusa as a first language in the process of learning Kiswahili as a second language. The study was conducted in Rungwe district in Kiwira and Nkunga wards. It involved Nyakyusa informants in Mbeya region.

\section{G. Languages of the Study}

This section provides a historical background and linguistic features of Kinyakyusa and Kiswahili respectively.

\section{H. Historical Background of Kinyakyusa}

Kinyakyusa is a Bantu language which is classified as M.31 (Guthrie, 1948, Maho, 2003). Kinyakyusa is mainly spoken in three districts of Kyela and Rungwe in Tanzania and Karonga in Malawi where it is called Konde. The native Nyakyusa people live in permanent villages which are politically recognized areas with administratively known borders or just an area for personal identification.

\section{The Major Dialects of Kinyakyusa}

Johnston (1919) identified two dialects of Kinyakyusa, namely kinyi-kiusa spoken by Nyakyusa people (Awanyakiusa) inhabiting the lake Nyasa plains and Mwamba or Iki-kukwe spoken by people inhabiting the hills (Abamwamba or Abakukwe). Wilson (1963) presents two distinct Kinyakyusa speaking people, namely Aba-Ngonde ( people of the lake plains) and Aba-Mwamba (People of the hills).

\section{J. Nyakyusa Language Phonology}

Phonology is a very large and active pattern of a language. It relates to the phonetic events of speech to grammatical units operating at the morphological, lexical, syntactic and semantic levels of language. Consonants or vowels in the phonology of a given language can occur in different locations depending on the syllable structures and different environmental contexts. For any given consonant or vowel, the range of possible locations is constrained by the phonology of the language. For example, zloty cannot be a native word in English, because the sequence /z/ breaks the rules about contextual occurrences in syllable initial structural position of the /z/ and /// consonants (Laver, 1995:38).

\section{Kinyakyusa Vowels}

Vowels are sonorous, syllabic sounds made with the vocal tract more open than it is for consonant and glide articulations (O'Grady,1997 ). Vowels are sounds produced with less restriction of air from the lungs. Vowels are normally described with reference to four criteria as suggested by Crystal (1997: 155):

i) The part of the tongue that is raised-front, center, or back. 
ii) The extent to which the tongue rises in the direction of the palate. Normally, three or four degrees are recognized: high, mid and low. Alternatively, tongue height can be described as close, mid-close, mid- open and open.

iii) The position of the soft palate- raised for oral vowels, and lowered for vowels which have been nasalized.

iv) The kind of opening made at the lips- resulting into various degrees of lip rounding or spreading.

The figure 1 below shows 7 Kinyakyusa vowel phonemes.

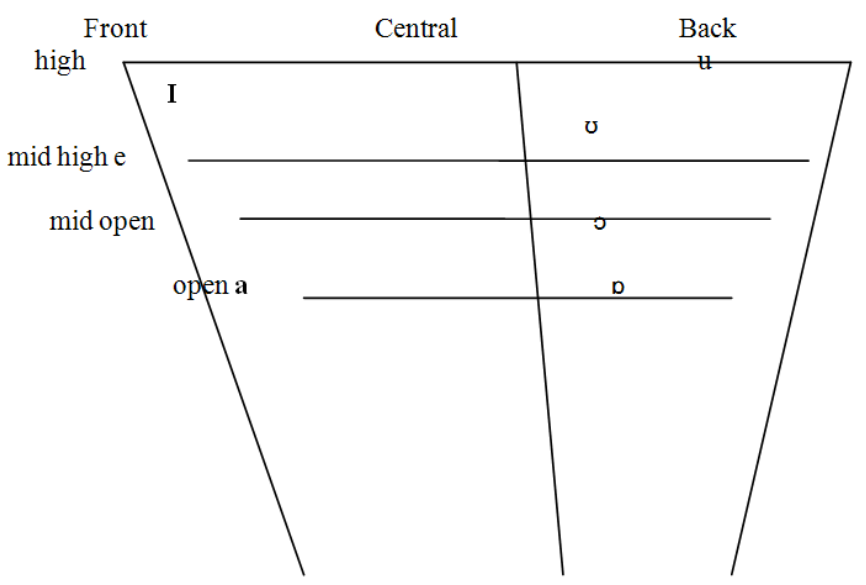

Figure 1: Kinyakyusa Vowel Phonemes

Examples of Kinyakyusa vowels

2. High front vowel /I/ -ikikota 'chair'

Ikiigalilo 'lock'

Mid high front vowel /e/- egana 'match, resemble'

embeesya 'take or show around'

Open front vowel / a/- amasimbi 'cocoyam'

High back vowel /u/- ubukuuje 'hurry'

/ $/$ - ubukabi 'richness'

Mid open back vowel / $/$ /-mooki 'in where'

Open back vowel / $\boldsymbol{w}$ - onga 'suck'

Kinyakyusa consonants

Consonants are sounds produced with restriction of air passage. Crystal (1997: 157) argues that consonants are described with reference to six criteria. These are as follows:

i) The source of the air stream-whether from the lungs (pulmonic) or from some other source (non-pulmonic)

ii) The direction of the air stream -whether moving outwards (egressive) or inwards (ingressive).

iii) The state of vibration of the vocal folds- whether vibrating (voiced) or not (voiceless).

iv) The position of the soft palate - whether raised (oral) or lowered (nasal)

v) The place of articulation in the vocal tract.

vi) The manner of articulation.

The following table 1 shows place and manner of articulation of the 15 Nyakyusa consonant sounds.

TABLE 1:

KINYAKYUSA CONSONANTS

\begin{tabular}{|c|c|c|c|c|c|c|c|}
\hline \multirow{2}{*}{$\begin{array}{l}\text { Manner of } \\
\text { Articulation }\end{array}$} & \multicolumn{7}{|c|}{ Place of Articulation } \\
\hline & Bilabial & Bilabial-dental & Dental & Alveolar & Palatal & Velar & Glottal \\
\hline Plosives/Stops & $\mathbf{P}$ & & & $\mathbf{T}$ & & $\mathbf{k}$ & \\
\hline Fricatives & B & f & & $\mathbf{S}$ & & & h \\
\hline Affricates & & & & & & $\gamma$ & \\
\hline Nasals & M & & & $\mathbf{N}$ & $\mathrm{n}$ & y & \\
\hline Liquids & & & & $\mathbf{L}$ & & & \\
\hline \multicolumn{8}{|l|}{ Trill } \\
\hline Approximants & $\mathbf{W}$ & & & & $\overline{\mathbf{j}}$ & & \\
\hline
\end{tabular}

Nyakyusa language consonant phonemes can be exemplified as follows:

3. (a) Plosives

Bilabial /p/ panja 'outside' pakina 'on Thursday' pabugono 'sleeping place'

Alveolar It/ tuusya 'rest' taluka 'be born', tabula 'pay back'

Velar /k/ kasya 'encourage' kinda 'pass' kupusya 'over turn'

(b) Fricatives 
Bilabial //ק/ abandu 'people' bujila 'repeat'bopa 'run'

Bilabial dental /f/ funja harvest' fuufu 'ripe', fisa 'hide'

Alveolar /s/ simya 'put out', sisiila 'close eyes', suuma 'ask for'

Glottal /h/ hinja 'slaughter', heehaw 'whisper', hobola 'loosen'

(c) Affricates

Velar $/ \gamma /$ ndaga 'thank you', gona 'sleep', gumbe 'zool baboon'

(d) Nasals

Bilabial /m/ manyisya 'teach', mila 'swallow', moga 'dance'

Alveolar/n/ nusya 'smell', nosya 'decorate', ndili 'when'

Palatal $/ n /$ nyukula 'pull out', nyonyofya 'attract', nyeela 'jump'

Velar/y/ ing'osi 'sheep', ing'ombe 'cow', ingong'ondelo 'wood pecker'

(e) Liquids

Alveolar /l/ lapa 'swear', lekana 'get separated', londa 'want'

(f) Approximants

Bilabial /w/ umwifwa 'thorn', umwimi 'miser', jwiba 'sink'

Palatal /j/ joola 'gather (in piles), jubika 'soak', jigisya 'shake'

\section{K. Kiswahili Phonological Inventory}

Standard Kiswahili phonology is divided into two branches, namely:

(i) Segmental phonology, which deals with sounds (phonemes) and allophones, and

(ii) Suprasegmental phonology, which deals with features like intonation, syllable, tone, rhythm, and stress (Mgullu, 1999:48). Phonological inventory in Kiswahili includes segmental phonology (phonemes) which is divided into two groups, namely vowel and consonant phonemes.

\section{Vowel Phonemes}

Vowels are sounds produced without a complete closure in the mouth. Vowels are usually voiced, i.e when they are articulated, the vocal cords tend to vibrate. Thus, vowels are those units of sound which function between syllables. There are five cardinal vowels in Kiswahili: /a/, /e/, /i/, /o/, and /u/. Hyman (2003) comments that Bantu languages have canonically 7 or 5 term vowel system; Kiswahili has a 5 term vowel system. These five vowel are the ones which are taught for the students who are learning Kiswahili and standard Kiswahili in many countries which are using this language and for the students who are learning the language as a L2/FL. Figure 2 below illustrates a summary of 5 vowels in Kiswahili.

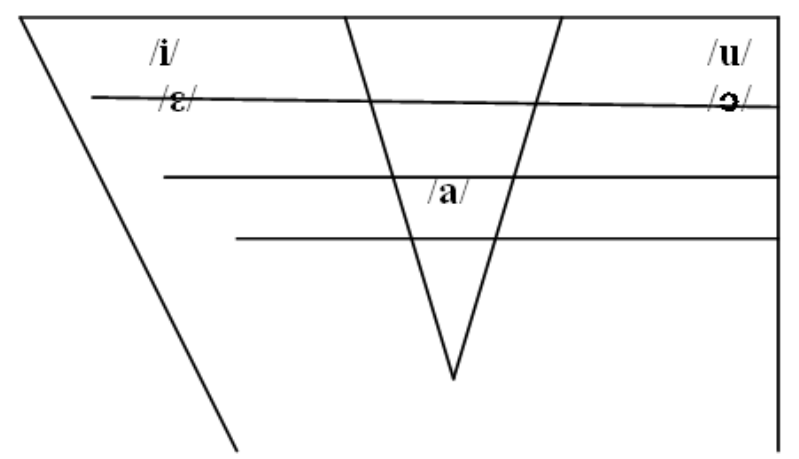

Figure 2: Standard Kiswahili vowel Phonemes Source: Mgullu (1999: 66)

Examples,

5. i) Mid-low vowel /a/ example; ana 'have/has'

ii) Front, mid-low vowel /\&/ example; embwe 'kind of glue'

iii) Front, high vowel /i/ example; itikia 'respond'

iv) Back, mid-low vowel //s/ example; ona 'see'

v) Back, high vowel /u/ example; uma 'bite'

\section{Consonant Phonemes}

These are sounds produced by closure or narrowing of the vocal tract so that the air flow either is completely blocked out or restricted to produce an audible friction. Kiswahili has 26 consonant phonemes which are categorized using two principles:

i) Place of articulation

ii) Manner of articulation

Table 3 below shows place and manner of Kiswahili consonant sounds 
TABLE 2:

STANDARD KISWAHILI CONSONANT PHONEMES

\begin{tabular}{|c|c|c|c|c|c|c|c|}
\hline \multirow{2}{*}{$\begin{array}{l}\text { Manner of } \\
\text { Articula-tion }\end{array}$} & \multicolumn{7}{|c|}{ Place of Articulation } \\
\hline & Bilabial & Bilabial-dental & Dental & Alveolar & Palatal & Velar & Glottal \\
\hline Plosives/Stops & $\begin{array}{l}\text { p } \\
\text { b }\end{array}$ & & & $\begin{array}{l}\mathbf{T} \\
\mathbf{d}\end{array}$ & & $\begin{array}{l}\mathbf{k} \\
\mathbf{g}\end{array}$ & \\
\hline Fricative & $\mathbf{m}$ & $\begin{array}{l}\mathbf{f} \\
\mathbf{v}\end{array}$ & & $\begin{array}{l}\mathbf{S} \\
\mathbf{Z}\end{array}$ & $\int$ & $\gamma$ & $\mathbf{h}$ \\
\hline \multicolumn{8}{|l|}{ Affricates } \\
\hline Nasal & M & & & $\mathbf{N}$ & n & y & \\
\hline Lateral & & & & $\mathbf{L}$ & & & \\
\hline Trill & & & & $\mathbf{R}$ & & & \\
\hline Approximants & $\mathbf{W}$ & & & & $\mathbf{j}$ & & \\
\hline
\end{tabular}

These consonant phonemes can be exemplified as follows:

(a) Plosives/Stops

a) Bilabial plosives/stops / $p$, b / example; panda, 'plant', biki 'pen'

b) Alveolar plosives/stops /t, $d$ / example; taka 'need', dawa 'medicine'

c) Velar plosives/stops $/ k, g / \quad$ example; $\boldsymbol{k a t a}$ 'cut', ganda 'freeze'

(b) Fricatives

a) Bilabial fricative sound $/ \mathrm{m} /$ example; $\boldsymbol{m}$ to 'river'

b) Bilabial-dental fricative sounds /f, $v$ / example; faida 'interest', vita 'war'

c) Dental fricative sounds / $\theta$, $/$ / example; thawabu 'gift', dhana 'concept'

d) Alveolar fricative sounds $/ s$, $z$ / example; samani 'furniture', zana 'apparatus'

e) Palatal fricative sound $/ /$ / example; shati 'shirt'

f) Velar fricative sounds / $\gamma$ / example; $\boldsymbol{k h}$ aa 'expression of anger', ghala 'storehouse'

g) Glottal fricative sound $/ h$ /example; haya 'shame'

(c) Affricates

Palatal affricates $/ t$ ], $d 3$ / example; chanuo 'comb', jaza 'fill'

(d) Nasals

a) Bilabial nasal sound /m / example; majira 'season'

b) Alveolar nasal sound / $n$ / example; nabii 'prohet'

c) Palatal nasal sound $/ n$ / example; ny anya 'tomatoes'

d) Velar nasal sound/ $y /$ example; ng'ombe 'cow'

(e) Lateral

Alveolar lateral sound /l/ example; laza lay'

(f) Trill

Alveolar trill /r / example; ramani 'map'

(g) Approximants

a) Bilabial approximants sound /w/ example; weka, 'put'

b) Palatal approximants /j / example; yatima 'orphan'

\section{Theoretical Framework}

The current study of the role of Kinyakyusa as a first language in learning Kiswahili as a second language is based on the Contrastive Analysis Hypothesis. Contrastive Analysis is a way of comparing and contrasting various linguistic features of two languages. For example sound systems, grammatical structures, vocabulary systems, writing systems and above all cultural aspects of two languages. The basic assumption of Contrastive Analysis in learning an L2, involves transferring the linguistic forms and meanings of the L1 to an L2 by learning a set of habits. Contrastive Analysts like Lado (1957) and Selinker (1992) argue that some languages are easier to learn than others because of similarity of some language patterns in both languages as the learner transfers experienced knowledge from first language to second language. Also where languages differ greatly in structure the learner will face some difficulties in the process of learning the second language as her/his former knowledge from L1 language may hinder learning L2 (Lado 1957). Thus, Contrastive Analysis Hypothesis is based on three main theoretical claims which are:

i) The learner expects to find equivalence between the L1 and L2.

ii) Learning the L2 requires the learner to learn something which is different from the L1.

iii) The learner finds it difficult to learn the new language when structures and patterns in the two languages differ (Selinker, 1992).

\section{LITERATURE REVIEW}


This is an account of what has been done or published on a problem area by scholars and researchers. This part includes motivation for language learning, the concept of language competence, phonological, morpho-syntactic and lexical influences of first /native languages in learning second/foreign languages.

\section{A. Motivation for Language Learning}

In real life, there are several reasons for a person to learn something. For example, language learners learn a language because they want to acquire, use, and communicate with those who speak the target language. Also, perhaps they learn a given language because they want to know their culture and learn about the country where the language is spoken (Nakanishi, 2002).

Motivation determines the extent of effort one exerts to fit into second or foreign language learning. The more motivation one has, the more effort one tends to put into learning the language. Thus, motivation leads to success in learning of any kind.

Gardner \& Lambert (1972) proposed that motivation is influenced by two orientations to language learning. An integrative orientation is typical of someone who identifies with and values the target language and community, and who approaches language study with the intention of joining that community. Such an individual is thought to have an internal, more enduring motivation for language study. Instrumentally, motivated learners on the other hand, are more likely to see language learning as enabling them to do other useful things, rather than having no special significance in it. Such learners will be motivated if they see language learning as having beneficial career prospects or something that will enable them to use transactional language with speakers of the second or foreign language (as cited in Nakanishi, 2002). Gardner and Lambert (1972) suggested that individuals with an integrative orientation would demonstrate greater motivational effect in learning L2, and thus achieve greater L2 competence.

\section{B. The Concept of Language Competence}

Valdes and Figueroa (1994) posit that knowing a language and knowing how to use it involves a mastery and control of a large number of interdependent components and elements that interact with one another and that are affected by the nature of the situation in which communication takes place. These components are manifest at different levels such as communicatve competence level as well as grammatical/ linguistic competence level.

\section{Phonological Influence of First Language in Learning Second Language}

Phonological awareness plays a major role in learning to read words, sentences or paragraphs in a particular language. It refers to the sounds of one's language in the processing of writing and speaking. So, it is the awareness of and access to the phonology of one's language. Successful acquisition of phonological representations needs accurate perception of phonemic intricacies. It is proved empirically that phonological awareness helps in the development of fine reading (Avanika, 2009).

Phonetics and phonology are the main parts of direct L1 influence on the pronunciation of second language learning (target language). In languages (L1 and L2) that are in the same family, there are articulatory similarities and differences in the utterance. For instance, Islam (2004) found similarities of some English and Bengali sounds but some particular sounds were different from the target language sounds in a very small but critical way in terms of articulation. The nearer these articulatory organs are to each, the more replacement of the L2 sounds occurs with L1 sounds. This replacement of L2 sounds with L1 endows the utterances with particular characteristics. Through this understanding, that is why one can identify Indian English, Chinese English or African English. The same applies to Tanzania where we can identify the speakers of Kiswahili either coming from Mtwara, Mbeya, Mwanza or Zanzibar relying to pronunciation of words as are influenced by their first languages. However, learners of higher proficiency may often eradicate this L1 influence if they are more attentive to production of particular sound. Mostly if they are more exposed to the native target language speech.

There are some sounds in English which are more similar to some sounds in Bengali but which involve different articulatory organs. For example, English has labial dental fricative sounds like /f/ and /v/ where as Bengali has bilabial stops $/ \mathbf{p}^{\mathbf{h}} /$ and $/ \mathbf{b}^{\mathbf{h}} /$. It happens that in pronouncing those two English sounds, Bengali speakers use both their lips instead of using the upper teeth and the lower lip. Hence, all the words with these sounds are heard as aspirated bilabial plosives rather than voiceless bilabial dental fricative sound /f/ or voiced bilabial dental fricative sound /v/. Example of words that be can given from the conversation are like fine, very, fish, etc. However native English speaker may confuse these words as aspirated $/ \mathbf{p}^{\mathbf{h}} /$ and $/ \mathbf{b}^{\mathbf{h}} /$ (Islam, 2004).

The English sounds like voiced alveolar fricative sound /z/, voiced palatoalveolar afficate sound /dz/ and voiced palatoalveolar fricate sound / $/$ are similar to two types of /z/ and /dz / sounds in Bengali. But a sound like /z/ often creates problems to all types of learners at the initial level. They cannot often produce the actual / $3 /$ /sound in the word like 'closure'. Instead they produce this sound either as $/ \mathbf{d} \mathbf{3} /$ or akin to voiceless palatoalveolar fricative sound / /. Here confusion may also arise to the listener due to this mispronunciation (Islam, 2004).

Lexical judgment tests using Japanese Kana (a syllabic script consisting of Hiragana and Katakana) were given to native English and native Chinese learners of Japanese. The visual familiarity and length in test words were controlled to examine the involvement of phonological or visual coding in word recognition strategies. The responses of the English and Chinese subjects were compared on the basis of observed reaction time. The results indicated that (a) 
Chinese subjects relied more on visual information in L2 Japanese kana words than did English subjects and (b) English subjects utilized the phonological information in Japanese kana words more than did Chinese subjects. Accordingly, these findings demonstrated that native speakers of English and Chinese utilized different word recognition strategies due to L1 orthographic characteristics, and such L1 word recognition strategies were transferred into L2 Japanese kana word recognition (Chikamstu, 1996).

Transfer from the L1 to the 12 involves both use and acquisition i.e. it may affect both the processes of speaking in the short term and the processes of learning over a period of time. The influence of the L1 on the L2 is obvious from our everyday experience. For example, most native speakers of English can tell whether an L2 user comes from Japan, German, France, or Spain (Cook, 2008).

Bebout, (1985) found that writing system of Spanish adult learners of English as L2 has L1 influence as they transfer spelling. Adult Spanish learners of English show characteristic Spanish transfer mistakes involving the double letters $\langle\mathbf{r r}\rangle$ and $\langle\mathbf{l l}\rangle$ and transpositions involving $\langle\mathbf{l}\rangle$ and $\langle\mathbf{r}\rangle$ ). Some 38.5 percent of English spelling mistakes were made by 10 -year-old Welsh, whether from phonological interference in the L2 pronunciation, orthographic interference from Welsh sound/ letter rules, or transfer of cognate words (James 1998). Different L1s produce characteristic spelling mistakes in English; For instance; Japanese learners of English frequently confuse $\langle\mathbf{l}>$ and $\langle\mathbf{r}\rangle$ as in walmer, grobal and sarary (Cook, 2001), perhaps because of their well-known pronunciation difficulties with the sounds $/ \mathbf{l} /$ and $/ \mathbf{r} /$, perhaps partly because of the way that English loan words are spelled in the kana syllabic system in Japanese.

Research into phonological transfer has also progressed from list of phonemes to more general aspects. In the acquisition of English stress assignment by speakers of Polish and Hungarian, 95 percent of the mistakes consisted of transfer of L1 metrical settings (Archibald, 1993). English syllables were made to conform to the structure of the L1 by adding epenthetic syllables- [filoor] (Egyptian floor) [piliz] (Hindi please) and [iskul] (Bengali school) (Broselow ,1992) as cited in (Cook, 2008).

Bada (2001:8-9), investigated Japanese learners who were learning to pronounce English sounds. He observed that the Japanese found it difficult to pronounce English sounds. The results were as follows; the phoneme /d/ was observed to have been replaced with /t/ in word-final position only. This phoneme in both word-initial and word-medial positions does not pose any problem to Japanese learners in pronunciation because both the /d/ and /t/ phonemes appear in these two positions.

It has been observed that learner's speech is one of the most recognizable features of a L2 learner as it bears a certain resemblance to L1. It shows that some learners whose L1 is French for example, are likely to sound different from those whose L1 is German when they both speak English. For example,

\section{English target French speaker German speaker

have [ hoev] [aev] [hoef]

From the above example, the French speakers show that French lacks the phoneme /h/ while the German pronunciation can be traced to the fact that German learner transfers feature or rule from her/ his L1 to the L2 grammar as examples show in table 5 below.

TABLE 3:

THE PHONOLOGICAL TRANSFERS

\begin{tabular}{|l|l|l|l|}
\hline L1 & L2 & Example & Comment \\
\hline Spanish & English & I espeak English & $\begin{array}{l}\text { Spanish does not allow addition of s consonant } \\
\text { sequences word-initially. }\end{array}$ \\
\hline English & French & [ty] (you) $\rightarrow[$ tu] $]$ & $\begin{array}{l}\text { English does not have the front, rounded vowel [y]. } \\
\text { The English speaker substitutes the [u] sound. }\end{array}$ \\
\hline Quebec French & English & Over dere & The [ ठ] sound is replaced by [d] \\
\hline European French & English & Over zere & The [ ठ ] sound is replaced by [z] \\
\hline
\end{tabular}

Zabron (2012) investigated the challenges that face Finnish people in learning Kiswahili. His findings revealed that foreigners experience some phonological difficulties in the area of pronunciation. Some of sounds like /z/, /J/, / $/ \mathrm{l}$, /v/, $/ \mathrm{w} /, / \theta /$, /ð/, and non-syllabic of $/ \mathrm{m} /$ and $/ n /$ were very difficult for the Finnish students to pronounce.

\section{Existing Gap}

Despite the fact that studies have been conducted on the role of first language in learning second language, these studies seem to have been done in different countries mostly in European countries. Majority of the researchers used informants of first languages who were in higher learning institutions. That is, where the second languages are not used in the daily life environment. According to the existing literature, not much has been done on Bantu languages within the Tanzania context specifically to Kinyakyusa as L1. Therefore, this study intended to fill the gap left by previous studies by investigating the phonological influence of Kinyakyusa as L1 in learning Kiswahili as L2; where both Kinyakyusa and Kiswahili are Bantu languages. Also Kiswahili is a medium of instruction in primary schools and it is the national language in Tanzania whereas Kinyakyusa is among the Tanzanian community ethnic languages. The researcher has used informants from primary and secondary schools of lower class in remote rural areas.

\section{ReSEARCH Methodology}




\section{A. Research Design}

The research design used in this study is qualitative since the researcher investigated the influence of first language in learning the second language involving learners in their natural environment. Qualitative analysis helped the researcher to study individual performance closely. The researcher examined the presence or absence of phonological influence of Kinyakyusa as a first language in the process of learning Kiswahili as a second language.

The researcher conducted a pilot study before the main study was carried out. This helped the researcher in testing the variables, instruments of data collection, informants and selected methods of data collection with prepared questions intended to reveal the desired information.

The researcher collected information from the informants who are Nyakyusa in Rungwe district in Kiwira and Nkunga wards.Word lists and observations were used in collecting relevant information. In-depth interview with open ended questions were administered to the purposely selected informants. The collected information was summarized, described in detailed and tables were used in presenting findings.

\section{B. Area of the Study}

The area of the study was in Mbeya region, Rungwe district at Kiwira and Nkunga wards. Primary and secondary schools were selected purposely in the study taking into consideration those areas where Kinyakyusa is mostly spoken, that is, rural areas which include, Ibagha and Ibula primary schools with Kiwira secondary school in Kiwira ward. Likewise, Nkunga ward, Matweli and Lupepo with Nkunga secondary schools were involved.This is because these places are in remote areas where Nyakyusa are dominant and familiar to the researcher. Also, due to limited resources which include time, area for the study could not go beyond two wards.

Kiwira and Nkunga are administrative wards in Rungwe district of the Mbeya region south of Tanzania. According to the 2002 census, Kiwira ward had a total population of 20,119 and Nkunga 14,685. Kiwira coordinates $9^{\circ} 10 \mathrm{~S}$ $33^{\circ} 32 \mathrm{E}$.

\section{Sample Size and Sampling Techniques}

The study involved a sample of twenty four pupils of primary schools and eight students of secondary schools in lower classes who were selected randomly. Also a sample of eight teachers from four primary schools and two teachers from two secondary schools were selected deliberately. Thus seventeen informants from each ward that is Kiwira and Nkunga wards were selected to represent others. The researcher asked the informants from standard two, three, four and to count number one to twenty four. Then those who counted even numbers were selected to represent others.

That is, from each class two pupils were involved. The same in secondary schools four students form one students conversant with Kinyakyusa and Kiswahili were selected randomly. Six teachers teaching Kiswahili as a subject in both primary and secondary schools were selected. That is, in each primary school two teachers teaching Kiswahili as subject in lower classes were selected. Like wise in each secondary school one teacher teaching Kiswahili as subject in form one was selected for the study.

\section{Data Collection Techniques}

Four research techniques were used by the researcher in collecting information. These are questionnaires, word lists, interviews and observations.

\section{Word lists}

The researcher presented an oral reading and asked the informants to read it loudly. A total of 20 Kiswahili words were used. These words had hypothesized sounds that Nyakyusa speakers would face some difficulties in pronouncing them properly since Kinyakyusa phonology inventory does not have them.

Also some words with sounds that are found in both Kinyakyusa and Kiswahili were presented. The informants were asked to read those words loudly with the researcher listening carefully at the same time writing in the note book and recording them. This task was used for testing pronunciation so as to detect any phonological influence of the first language in learning second language.

\section{Interviews}

In this study, interviews were conducted to six informants, that is Nyakyusa primary school and secondary teachers in Kiwira and Nkunga wards respectively. The researcher asked the informants some questions about the study of which they replied while the researcher listened carefully and noted in the notebook.

\section{Observations}

The researcher collected descriptive data by observing learners engaged in the second language learning in their daily life. For example, the way they pronounced words, used lexical items and their formulation of grammatical sentences. The researcher was involved in different conversations through different contexts such as at home, at school when teachers were teaching as well as political, religious and community development meetings. Through this way, the researcher noted in the notebook the information related to the study.

\section{E. Data Analysis Procedure}

The raw data from informants were textual. They were processed into useful information. The researcher derived a set of categories in the data obtained from word lists, interviews and observations. The Data were categorized by 
looking for commonalities, regularities/patterns across the data variations. These categories were then investigated by cross-referencing to see whether there were relationships that would assist in understanding the phonological influence of the first language in learning the second language.

Finally, these data were presented descriptively and in terms of tables.

\section{F. Reliability and Validity of the Research Study}

Researchers used triangulation in the process of collecting and analyzing data. Carefull listening and note taking during interview and reading word lists assisted the researcher by referring to them during data analysis. The data collected were analyzed the same day after the interview so as to keep memory. Triangulation has been found an important methodology in naturalistic and qualitative approaches to evaluation. This is because it helped the researcher in controling bias and establishing valid propositions.

Generally, researchers adhered to the three basic ethical principles which are respect for persons, beneficience and justice as suggested by Krysik (2007: 32).

\section{Data Presentation, ANALysis AND Discussion}

\section{A. Phonological Influences of Kinyakyusa in Learning Kiswahili as a Second Language}

Generally, phonology involves two studies. It includes the study of production, transmission and reception of speech sounds (phonetics) and the study of the sounds and sound patterns of a specific language (phonemics). Human beings are capable of producing an infinite number of sounds but no language uses more than a small proportion of this infinite set and no two human languages make use of exactly the same set of sounds. It has been observed that when we speak, there is continuous movement of such organs as the tongue, the velum (soft palate), the lips and the lungs. Human beings put spaces between individual words in the written medium but there are no similar spaces in speech (Todd, 1987).

Phonological influence of L1 in learning L2 can be revealed in phonemic differences, segmental errors (i.e. errors concerning vowel and consonant), supra-segmental errors regarding stress, tone rhythm and other factors. In case of pronunciation stress is essential for listeners to recognize a word class because it may affect syllables and the segments that constitute certain nouns and verbs such as between COMbine and comBINE (Odlin, 1989: 116). Odlin also mentions Bansal's (1976) opinion about English in India where unintelligibility and misidentification mostly arises due to errors in the stress patterns in the pronunciation in English.

Kinyakyusa language as one among the Bantu languages has some sounds that are similar to Kiswahili. These similarities of such sounds between two languages play a great role in the process of learning a second language. As normal, children in rural areas acquire their native languages before L2 the process that simplifies the learning of second language.

For the sake of specificity, this study is based only on sounds (phonemes) leaving out the other aspects of prosodic features which are intonation, pitch, syllable, tone, rhythm, accent, and stress. The researcher concentrated on sounds since the speaking skill which is basic in learning language involves sounds.

The word lists comprised of Kiswahili words with phonemes that were hypothesized that Nyakyusa people face some difficulties in pronouncing them. Skutnabb-Kangas (1981) cited by Orekan (2011) found that first language is the language that one thinks, dreams and counts in. The similarities of sounds enable the learner to transfer the same sounds into the second language during learning process. The following table 5 shows sounds that are similar from Kinyakyusa to Kiswahili

TABLE 4:

THE SIMILAR SOUNDS FROM KINYAKYUSA TO KISWAHILI LANGUAGE

\begin{tabular}{|c|c|c|c|c|c|c|}
\hline \multicolumn{2}{|c|}{ Kinyakyusa } & \multicolumn{2}{|c|}{ Kiswahili } & \multicolumn{2}{|c|}{ Kiswahili Examples } & \multirow{2}{*}{$\begin{array}{l}\text { English } \\
\text { Literal meaning }\end{array}$} \\
\hline Orth & Pronunc. & Orth & $\begin{array}{l}\text { Pronu } \\
\text { nc. }\end{array}$ & $\begin{array}{l}\text { Kinyakyusa } \\
\text { words examples }\end{array}$ & $\begin{array}{l}\text { Kiswahili words } \\
\text { examples }\end{array}$ & \\
\hline $\mathrm{P}$ & $/ p /$ & $\mathrm{p}$ & $/ p /$ & poka & pokonya & rob \\
\hline $\mathrm{t}$ & $\mid t /$ & $\mathrm{t}$ & $|t|$ & tamya & tabisha & disturb \\
\hline $\mathrm{k}$ & $\mathrm{k} / \mathrm{s}$ & $\mathrm{k}$ & $/ k /$ & kaabila & kawia & delay \\
\hline $\mathrm{f}$ & $|f|$ & $\mathrm{f}$ & $|f|$ & fuga & fuga & keep livestock \\
\hline $\mathrm{s}$ & $/ s /$ & $\mathrm{s}$ & $/ s /$ & suka & safisha & wash \\
\hline $\mathrm{h}$ & h/ & $\mathrm{h}$ & $/ h /$ & halisya & harisha & have diarhoea \\
\hline 1 & Ml & 1 & /l/ & lila & lia & cry \\
\hline $\mathrm{m}$ & $/ \mathrm{m} /$ & $\mathrm{m}$ & $/ \mathrm{m} /$ & mpiki & $\mathbf{m t i}$ & \\
\hline $\mathrm{n}$ & $\ln /$ & $\mathrm{n}$ & $\ln /$ & nkati & ndani & inside of \\
\hline ng' & $|\eta|$ & ng' & $\mid \eta /$ & ng'ombe & ng'ombe & cow \\
\hline $\mathrm{w}$ & $/ w /$ & $\mathrm{w}$ & $/ w /$ & bwima & kusimama & while standing \\
\hline j & /jl & $\mathrm{j}$ & /j/ & jeela & jaa & be abundant \\
\hline ny & $/ \mathrm{n} /$ & ny & $/ \mathrm{n} /$ & nyegeesya & tekenya & tickle \\
\hline
\end{tabular}

The data from table 6 above show that there are sounds from Kinyakyusa that are similar to Kiswahili, for instance: (a) /p/ in word like pija (L1) pika (L2) 'cook' 
(b) /l/ in word like tuula (L1) tua (L2) 'help'

(c) /k/ in word kosomola (L1) kohoa (L2) 'cough'

(d) /f/in word fumbula (L1) fumbua (L2) 'reveal'

(e) /s/ in word sipuka (L1) sinzia (L2) 'doze'

(f) $/ \mathbf{h} /$ in word hangajika (L1) hangaika (L2) 'be worried'

(g) /l/ in word lisya (L1) liza (L2) ' cause some body to cry'

From table 5 above, it is true that Kinyakyusa has sounds that are similar to Kiswahili language. Since children in rural areas do acquire Kinyakyusa first then later Kiswahili, there is high possibility for the learner to transfer knowledge from L1 to L2. Sarig (1988) investigated the relative contribution of L1 reading strategies and L2 proficiency to L2 reading to female students aged 17 who had Hebrew as L1 and English an L2. She found that the identification of the main idea of a text was achieved in the same way in L2 as in L1.

Through the word lists that were prepared by the researcher as was predicted that there were Kiswahili phonemes that Nyakyusa speakers face difficulties in pronouncing, it was found that some informants especially of primary schools in standard two to four in rural areas pronounce Kiswahili words incorrectly. This is because they are affected by Kinyakyusa is used in the society more than Kiswahili. The words that were heard with incorrect pronunciation were as follows:
(a) kura 'kulal 'vote'
(b) ruka 'lukal 'jump'
(c) taratibu /talatibu/ 'slowly'
(d) darasa /dalasal 'classroom'
(e) karanga /kalanga/ 'groundnuts'
(f) mahari /mahali/ 'bride bribe'.
(g) rafiki lafiki/ 'friend'

From the data 21 above, it was found that informants failed to pronounce correctly voiced alveolar trill sound /r/ as was pronounced as voiced alveolar lateral sound ///. This is because Kinyakyusa has no voiced alveolar trill sound /r/ but has voiced alveolar lateral sound /l/. In some words, errors in pronunciation brought no changes in word meaning but in other words errors resulted into change of former word meaning. For example:

Kагати (celebration) was pronounced as kalamu (an instrument used for writing on the paper)

In addition, the voiced alveolar fricative sound /z/ was pronounced as voiceless alveolar fricative sound /s/ as shown below:

$\begin{array}{lll}\text { zamani } & \text { /samanil } & \text { 'long time ago'. } \\ \text { zaa } & \text { /saal } & \text { 'give birth'. } \\ \text { zote } & \text { /sotel } & \text { 'all'. } \\ \text { zizi } & \text { /sisi/ } & \text { 'cows' hut'. }\end{array}$

It is shown in the data 23 above that the informants' errors in pronunciation resulted into change of the intended meaning especially when they were pronounced singly, that is out of the context. For instance zamani which means long time ago was pronounced as samani which means furniture, zaa which means give birth or produce was pronounced as saa which means a watch/ a clock. Thus these words when they were pronounced out of context brought irrelevant meanings but when used in the context it was easier to understand them. For example:

Zamani watu walikuwa wachache ukilingaganisha na sasa

/samani watu walikuwa wachache ukilinganisha na sasal

'In past there were few people compared to the present'

Although there are errors in pronouncing zamani and samani being used in the context it became easier to detect error and know what such an utterance meant.

The problem is not only limited to the above sounds that the lay Nyakyusa speaker faces difficulties in pronouncing standard Kiswahili words, but also there are others like voiceless palatal alveolar affricate sound $/ t \boldsymbol{t} /$ which was almost always pronounced as ky. For example:

$\begin{array}{lll}\text { changu } & \text { Kyangul 'mine' } \\ \text { chai } & \text { Kyai/ } & \text { 'tea' } \\ \text { chama } & \text { kyamal } & \text { 'party' } \\ \text { chuma } & \text { kyumal 'iron' } \\ \text { chura } & \text { kyula/ 'frog' }\end{array}$

This kind of errors is the result of phonological process known as palatalization. Palatalization is the process of consonant assimilation. It is when a non-palatal consonant acquires some palatal characteristics in its articulation due to the following glide or vowel. For instance the word

chai its internal morphology is $k i+a i$

From the word chai the glide process takes place as follows:

$k i \rightarrow$
$i \rightarrow / y / /+I$
$k y a i$ 
From the above example, high front vowel $\mathbf{i}$ changes into glide $\mathbf{y}$ where there is a sound vowel which follows after morpheme boundary. The palatalization process is similar in Nupe, a West African language where consonants are palatalized before front vowels. For instance,

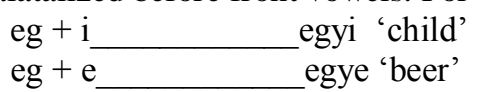

Source: Schame (1973) as cited in Massamba (2007: 108).

Also the voiceless dental fricative sound $/ \boldsymbol{\theta} /$ was pronounced as voiceless alveolar fricative sound $/ \mathbf{s} /$ as shown below:

thelathini /selasini/ 'thirty'

themanini /semanini/ 'eighty'

thamani /samani/ 'value'

theluthi /selusi/ ......' one third'

This is because Kinyakyusa has no voiceless dental fricative sound $/ \boldsymbol{\theta} /$ hence its speakers do pronounce the sound /s/ as voiceless alveolar fricative.

This kind of influence of the first language in learning the second language is supported by Laver (1995:79), who argued that, the deviations in performance of a foreign language by a speaker from native-speaker-like norms of pronunciation are almost all directly attributable to the influence of differences between the phonetic and phonological patterns of the foreign language and the speaker's own native language. For example, Received Pronunciation (herein RP) distinguishes two phonemes voiceless dental fricative sound $/ \boldsymbol{\theta} /$ and the voiced alveolar fricative sound /z/, that French speakers who use only the voiced alveolar fricative sound /z/. Similarly where the RP vowel system distinguishes between /I/ and /i/ (as in hid /hid/) and heed /hid/ respectively) French uses only /i/.

Also the data show that, some informants failed to pronounce in standard form the voiceless palatal alveolar fricative sound $\mathcal{S}$ as they pronounced it as $\mathbf{s}$ or $\mathbf{s y}$ as the data show in the following words:

shangaza /sangasal 'amaze'

shuka 'syukal 'come down'

shule /syule/ 'school'

shangazi /sangasi/ 'aunt'

This kind of error is the result of absence of voiceless palatal alveolar fricative sound $/ /$ in Nyakyusa language. Hence, speakers of L1 use two alternating sounds which are /sy/ and /s/ which act as allophones of voiceless palatal alveolar fricative sound $\Lambda /$.

Another sound that Nyakyusa learners of Kiswahili face some difficulties in pronouncing correctly is voiceless labiodental fricative sound /f/ which almost always was pronounced as fw as data below show in example 28 :

fanya /fwanyal 'do'

fagia /fwagial 'sweep'

faulu /fwaulu/ 'pass'

fahamu /fwahamu/ 'understand'

The findings of the data 28 above show errors in pronunciation. This is because, in Kinyakyusa, some sounds are pronounced differently from their orthography.

When the researcher was analyzing the recorded sounds, it was found that sound /y/ was always almost pronounced as / j/ as in the following words:

$\begin{array}{lll}\text { yohana ljohanal } & \text { 'John' } \\ \text { yule } & \text { /jule/ } & \text { 'that' } \\ \text { yeremia } & \text { /jeremia/ } & \text { Yeremiah' } \\ \text { yote } & \text { /jotel } & \text { 'all' }\end{array}$

The palatal glide sound /y/ was pronounced as / $\mathrm{j} /$ similar to English palatal glide. This is because there are some Nyakyusa sounds that are pronounced differently from their orthography.

In addition, there was the voiced bilabial plosive sound /b/ that was pronounced as / $\boldsymbol{\beta} /$ different from native speaker of Kiswahili. This is because there is no plosive voiced sound /b/ in Kinyakyusa. For example,
30. baba Khabhal 'father'
baraza /bhalasal 'court'
bandari /bhandari/ 'harbour'
bendera /bhendela/ ' flag'

In general, the data show Kinyakyusa phonological influences permeate in Kiswahili as learners transfer some sounds from their first language when learning second language. This is supported by Flege (1999), that the initial point for L2 speech development is the L1 phonetic groups. For example, a study involving Spanish L1-English L2 with children aged 4 to 7 years, found them to be more accurate in their production of phonemes that are shared between two languages than of the phonemes that are present only in the English as L2.

\section{B. The Way Theoretical Framework is Related to This Study}

Contrastive Analysis Hypothesis as the theoretical framework to this study has been fulfilled. This Contrastive Analysis Hypothesis is based on three main theoretical claims. These are, the learner expects to find equivalence between the L1 and L2, learning the L2 requires the learner to learn something which is different from the L1 and the 
learner finds it difficult to learn the new language when structures and patterns in the the two languages differ (Selinker, 1992).

This study involved Kinyakyusa as L1 and Kiswahili as L2 and the findings reveal that learners found some equivalence and diffferences between Kinyakyusa and Kiswahili. Where there were similarities, the learner learnt L2 without greater difficulties in sharp contrast where there were some differences from L1 to L2. Thus, the learner of L2 required to learn something which was different from L1.

\section{CONCLUSION AND RECOMMENDATIONS}

\section{A. Conclusion}

This study has examined the phonological influence of Kinyakyusa as a first language in learning Kiswahili as a second language. The study found that both Kinyakyusa and Kiswahili are Bantu languages. Thus, inspite of some differences between them as each language has its own features, there are great similarities between Kinyakyusa and Kiswahili that greatly facilitate in learning Kiswahili as a second language. This correlates with Zabron (2012:127) who by quoting Selinker (1992) argues, that learners find it easy to learn a language when structures and patterns in the two languages are similar and find it difficult to learn the new language when two languages differ.

\section{B. Recommendations}

In this study recommendations are of two kinds, notably recommendations for action and for further research.

\section{Recommendations for Action}

Academicians should be writing on first languages, that is first languages should be kept in a written form. This study has examined some first languages and came to the conclusion that such languages are not in written form, hence affecting to some extent the learning process as learners face with insufficient reference during learning process.

Parents and community in general should expose their first/native languages to their children rather than devaluing them and instead putting premium on foreign languages. The study found that there are some parents who purposely do not expose their first languages to their children thinking that it is useless to do so. Thus, children growing in such an atmosphere are deprived of potential their native languages. However, the current study believes that such languages are immense resource. Therefore, they should be taught to children in their formative years as prepations to equip them with potential resources of learning other second languages especially Kiswahili.

Teachers should consider the learner's first language when teaching a second language. This is because the learner's first language has influence in learning a second language.

Likewise,Tanzania language policy should explain how ethnic community languages can be supported. For eample, this can be done through assigning them some formal roles. This will add some values to ethnic community languages.

\section{Recommendations for Further Research}

It is suggested that this study should be conducted in larger area beyond the confines of the current study. This is because, due to limitation of resources in terms of funds and time, this study was conducted in Rungwe district involving only two wards.

It is also suggested that these studies should not only be confined to Kinyakyusa language but should also involve other ethnic languages by examining the roles they play in learning Kiswahili as a second language.

\section{REFERENCES}

[1] Archibald, J. (1993). Language Learnability and Second Language Phonology. The Acquisition of Metrical ParametersDordrecht: Kluwer.

[2] Bada, E. (2001). "The Reading Matrix", Native Language Influence on the Production of English Sounds by Japanese Learners 1 (2) 1-15.

[3] Bebout, L. (1985). "An error analysis of misspellings made by learners of English as a first and as a second language", Journal of Psycholinguistic Research, 14, 569-593.

[4] Broselow, E. (1992). "Non Obvious Transfer: on Predicting Epenthesis" in S. Gass and L. Selinker (eds), Language Transfer in Language Learning, Amsterdam.

[5] Collier, V.P. (1992). A synthesis of studies examining long term language minority student data on academic achievement, Bilingual Research Journal, 16 (1-2).

[6] Collier, V.P. (1995). Acquiring a Second Language for School, Directions in Language and Education, National Clearinghouse for Bilingual Education 1 (4) 1-8.

[7] Cook, V. (2001). Second Language Learning and Language Teaching, Arnold, London.

[8] Cook, V. (2008). Linguistics and Second Language Acquisition: One Person with Two Languages, https://doi.org/10.1002/9780470756409.ch20.

[9] Crystal, D. (1997). Encyclopedia of Language Second Edition, Cambridge University Press, New York.

[10] Endemann, K. (1900). "Zur Erklarung einer eigenthumlichen, Verbalform in Konde" in Mittheilungen Des Seminar Fur Orientalische Sprachen, vol.3: 93-95.

[11] Felberg, K. (1996). Nyakyusa-English-Swahili \& English-Nyakyusa Dictionary, Mkuki na Nyota Publishers, Dar es Salaam.

[12] Flege, J. E. G. Yeni-Komshian \& Liu.S. (1999). Age Constraints on Second Language Acquisition. Journal of Memory and Language 41, 78-104. 
[13] Gardner, R.C. \& Lambert, W.E. (1972). Attitudes and Motivation in Secondary Language Learning, Rowley, MA: Newbury House.

[14] Guthrie, M. (1948). The Classification of Bantu Languages. London: Oxford University Press.

[15] Hyman, L. (2003). Segmental Phonology. In Nurse, D \& Philipson, G (eds), The Bantu Languages. London: Routledge, 45.

[16] Islam, S. M. A. (2004). First Language Influence on the Spoken English Proficiency of Bengali Speakers, C-Essay in English, Hogskolan Dalama 1-36.

[17] James, C. (1998). Errors in Language Learning and Use: Exploring Error Analysis, Longman, London.

[18] Johnston, H.H. (1919). Comparative Studies of the Bantu Languages, Clarendon Press, Oxford.

[19] Krysik, J. L. \& Finn, J. (2007). Research for Effective Social Work Practice, Mc Graw Hill, Boston Burr Ridge.

[20] Lado, R. (1957). Linguistics Across Cultures, University of Michigan, Ann Arbor.

[21] Laver, J. (1995). Principles of Phonetics, Cambridge University Press, New York.

[22] Lotto, L. \& de Groot, M. B. (1998). "Effects of Learning Method and word type on Acquiring Vocabulary in an Unfamiliar Language", Language Learning, vol.3, pp 43-54.

[23] Maho, J. F. (2003). A Classification of the Bantu Languages: an Update of Guthries Referential System. Routlege Handbooks Online, http://www.routlegehandbooks.com/doi/10.4324/9780203987926.ch31.

[24] Massamba, D.P. B. (2007). Kiswahili Origins and The Bantu Divergence- Convergence Theory. Dar es Salaam: Institute of Kiswahili Research.

[25] Method, S. (2008). Aspects of Kinyakyusa Phonology. The case of Kimwamba Dialect, Unpublished Dissertation University of Dar es Salaam.

[26] Mgullu, R. S (1999). Mtaala wa Isimu: Fonetiki, Fonolojia ya Kiswahili. Nairobi: Longhorn Publishers.

[27] Nakanishi, T. (2002). "Critical Literature Review on Motivation”, Journal of Language and Linguistics, 1 (3), 278-287.

[28] O’Grady, W. (1997). Syntactic Development, University of Chicago, Chicago.

[29] Odlin, T. (1989). Language Transfer, Cambridge University Press, USA.

[30] Orekan, G. (2011). "Scottish Languages Review" Mother Tongue Medium as an Efficient Way of Changing Educational Disadvantages in Africa: The Case of Nigeria.

[31] Prince, P. (1996)."Second Language Vocabulary Learning: the role of context versus translations as a function of proficiency", The Modern Language Journal, 80, 478-493.

[32] Selinker, L. \& Gass, S.M. (1992), Second Language Acquisition third Edition, Routledge, 2Park Square.

[33] Todd, L. (1987). Introduction to Linguistics, Longman York Press, London.

[34] Valdes, G. \& Figueroa, R. (1994). Bilingualism and Testing: A special Case of Bias, Ablex Publishing, Norwood, NJ.

[35] Wilson, M. (1963). Good Company: A Study of Nyakyusa Age- Villages, Beacon Press, Boston.

[36] Zabron, P. (2012). Challenges Experienced by Foreigners in Learning Kiswahili in Higher Learning Institutions, MA. Linguistics UDOM (Unpublished dissertation).

Godson Robert Mtallo is an assistant lecturer in the department of Business Administartion at the College of Business Education (CBE) - Dodoma campus located in Dodoma region; the capital city of Tanzania. He holds a Bachelor degree in Education measuring in linguistics (Bed Arts - Linguistics) of the University of Dar es Salaam (UDSM) and a master degree in Linguistics (MA Linguistics) of the University of Dodoma. His main research interests is on applied linguistics especially on the languages of instruction; language teaching and learning. Currently, he teaches Business Communication Skills.

Harid Andrew Mwambula born in Rungwe district Mbeya region in Tanzania on $29^{\text {th }}$ January, 1975. Completed form four at Rungwe secondary school, form six in 2001 at Meta high school, certificate in education at Tukuyu Teachers' College in 1997, Diploma in education at Mpwapwa Teachers'Training College in 2005. Bachelor in education Languages atTeofilo Kisanji University in 2009 in Mbeya Tanzania and Masters of Arts in Linguistics at the University of Dodoma in 2013 in Dodoma Tanzania. He taught Primary schools and secondary schools. Currently he is an assistant lecturer at Tanzania Institute of Accountancy, Dar es Salaam - Tanzania. 